\title{
FRONTEIRAS EM DISCUSSÃO
}

\author{
Richard Miskolci
}

$\mathrm{Na}$ esteira dos estudos pós-coloniais, desenvolveu-se uma profícua linha de estudos socioantropológicos sobre o fenômeno da imigração que, após o 11 de setembro, encara o desafio de compreender o cenário do recrudescimento da xenofobia sob a retórica de segurança nos Estados Unidos e na Europa. Sintonizada com esses fenômenos, a Ciência Política brasileira dá uma contribuição valiosa para o estudo da cidadania e seus paradoxos por meio do livro Políticas de imigração na França e nos Estados Unidos, de Rossana Rocha Reis.

A obra preenche uma lacuna nos estudos brasileiros sobre imigração ao focá-lo sob a perspectiva das relações internacionais. Ao questionar uma relação direta e necessária entre nacionalidade e cidadania, alcança discussões de espectro maior e de relevância também para estudiosos das questões dos direitos humanos, das diferenças e do multiculturalismo.

O ponto de partida do estudo de Reis é uma concepção de fronteiras emprestada a Rogers Brubacker, a qual alude tanto "a externa, na qual o Estado definiria os critérios de entrada em seu território, e a interna, na qual ele definiria os critérios para inclusão na cidadania, principalmente mediante o acesso aos direitos políticos elementares" (REIS, 2007, p. 24). Ambas as fronteiras estão umbilicalmente ligadas por classificações de cunho cultural, econômico e político derivadas das histórias particulares de cada país.

A escolha dos Estados Unidos e da França como casos privilegiados de estudo se justifica por várias razões. Trata-se dos maiores receptores de imigrantes do mundo e potências historicamente imperialistas que gostam de se compreender quer como "a terra dos imigrantes" quer como "a pátria dos direitos humanos", mitos desconstruídos pela autora por meio de uma sofisticada articulação entre reconstituição histórica e análise sociológica.

O caso norte-americano é marcado pela construção da fronteira externa, base profícua para a criação do imaginário nacional americano desde o século XIX, com a grande expansão para o Oeste, as guerras com nativos e mexicanos, em suma, eventos históricos reescritos e reconstituídos segundo os interesses de cada época, popularizados por Hollywood e pela televisão ${ }^{1}$. Segundo Reis, há, de forma simplificada, quatro grandes períodos da história americana no que concerne aos imigrantes: um período que vai até aproximadamente a Primeira Guerra Mundial, em que vigorou a crença do nacionalismo cívico baseado na concepção da nação como um melting pot, posteriormente em uma ascensão do nativismo e restrição à imigração baseada em critérios raciais e religiosos, o que chega até a década de 1960, quando uma política associada aos interesses da luta contra o comunismo cria uma política mais liberal e baseada em direitos, até que, após os ataques de 11 de setembro de 2001, passa a vigorar um contexto marcado pela retórica da segurança. Vale ressaltar o cuidado e o critério da pesquisadora, que jamais apresenta cenários históricos desprovidos de contradições e lutas.

O caso francês é marcado pelo período de síntese republicana entre fins do século XIX e início do século XX, quando há "o apogeu do desenvolvimento de uma cultura nacional centralizadora que identifica a França como a Pátria das Luzes, dos direitos humanos, da revolução e do progresso" (idem, p. 115). Essa concepção universalista de cidadania não impediu que, na prática, fossem tratados diferentemente franceses da metrópole, da colônia e estrangeiros vivendo em território francês (idem, p. 117). Percebe-se que lá, desde o início, a questão das fronteiras internas foi a tônica das discussões sobre nacionalidade, cidadania e acesso a direitos. Para os imigrantes, o foco foi o grau de sua "adaptação" ou não à sociedade francesa, questão que, sob a máscara de um critério cultural, jamais encobriu o racismo e a xenofobia. Não é mero acaso o fato de a França ser o único país europeu a ter cogitado uma política de repatriamento forçado dos "indesejados".

1 Sobre a construção do Império Americano, há uma vasta literatura. Destaco a reflexão recente de Perry Anderson (2003), publicada como Força e consentimento: aspectos da hegemonia americana, e a contribuição monumental de Edward W. Said (2007) na reconstituição da construção cultural do Ocidente pela invenção de um "Outro" por meio do Orientalismo. 
Podemos compreender a importância de um olhar brasileiro sobre a política internacional dos direitos humanos em geral, e sobre a imigração em particular, a partir das sábias palavras de Edward W. Said, em Orientalismo, sobre como o conhecimento das ciências humanas é marcado pelas circunstâncias da realidade do observador (SAID, 2007, p. 39). No livro de Reis, não encontramos a perspectiva dos próprios norteamericanos e franceses, antes um olhar treinado pela realidade social e política de um país em que a cidadania é marcada por fronteiras internas que delimitam o acesso a direitos por meio de uma seletividade injusta.

É por meio desse olhar "de fora", que a professora do Departamento de Ciência Política da Universidade de São Paulo mostra a relação entre identidade e direitos como problematizadora da concepção de cidadania como direitos de um cidadão nacional. A relação com o exterior, com os estrangeiros, em suma, com os Outros, permite também compreender como essas nações se constituíram internamente. A fronteira externa é umbilicalmente ligada à interna, pois ela depende das concepções conflitantes de nação presentes dentro de um mesmo Estado (REIS, 2007, p. 49). Encontramo-nos, então, dentro das especificidades norte-americana e francesa e, ainda que paralelos diretos com o Brasil não sejam apresentados, é tentador pensar com Reis sobre nossos paradoxos do acesso seletivo à cidadania. Em uma democracia institucional, mas com acesso efetivo aos direitos impedidos pelos mais diversos fatores, Reis auxilia-nos a refletir sobre nossas fronteiras internas.

O paralelo com os Estados Unidos e a concepção de nação do melting pot convida a refletir sobre nosso mito da democracia racial que ainda marca as polêmicas recentes entre movimentos negros e os defensores de um ideal de homogeneidade nacional ${ }^{2}$. A polêmica parece reatualizar no contexto brasileiro o que representou a ascensão do multiculturalismo na sociedade norte-americana, mas tem componentes que apenas o conhecimento do caso francês permite apreciar de forma mais acurada. Percebe-se não apenas a particularidade histórica do acesso diferenciado à cidadania em cada país, mas também a importância de reflexões comparativas para lidar com uma problemática que exige levar as fronteiras a sério, sem as mitologizar.

O "consenso republicano" do acesso universal aos direitos por meio da cidadania francesa tende a obscurecer os processos de seletividade envolvidos nesse ideal. A nação como conjunto igualitário sublinha direitos iguais, mas também justifica a rejeição e até a supressão das diferenças. Vincula-se, assim, cidadania e neutralidade identitária, mantendo o mito da nacionalidade como porta de entrada universal para os direitos e a acolhida social. Por que se trata de um mito? Porque a universalidade dessa concepção de nacionalidade e, portanto, de cidadania e direitos, sempre se baseou no tratamento desigual entre os nacionais e os estrangeiros, mas, de forma mais sutil, também criou "graus" ou "modalidades" de cidadania entre os nacionais.

As fronteiras internas no Brasil não se referem tanto a nosso pequeno contingente de imigrantes, mas principalmente à população que nunca acedeu aos direitos de cidadania plena por razões discriminatórias as mais variadas: do evidente racismo que se procura não erradicar, da dominação masculina que emperra a aprovação do direito ao aborto até a homofobia não-criminalizada. Diante desse nosso contexto, são salutares as reflexões e análises de Reis sobre as concepções universalistas que marcam o caso francês e, de forma particular, também o brasileiro.

Uma imagem esclarecedora sobre as fronteiras internas é apresentada por Beatriz Preciado, teórica queer espanhola radicada na França. Em meio à controvérsia sobre o uso do véu nas escolas por parte das muçulmanas, que levou à proibição dele como intrusão da religião no espaço republicano laico do sistema educacional, Preciado aponta o caso de uma jovem muçulmana que, para manter a prescrição religiosa de não expor o cabelo ao escrutínio público e ainda assim poder ir à escola, optou por raspar a cabeça (CARRILLO, 2007, p. 403). A figura da jovem de cabeça raspada evoca associações múltiplas sobre o direito à diferença contestado pelo Estado francês e sua imagem lembra a dos judeus nos campos de concentração, a de lésbicas que decidiram evidenciar sua feminilidade diferenciada (e socialmente perseguida), assim como a de mulheres com câncer que passam pela quimioterapia. A jovem muçulmana de cabeça raspada é uma imagem-síntese de diferenças que um Estado universalista e uma sociedade preconceituosa desrespeitam sob o apregoado compromisso com a igualdade.

\footnotetext{
2 Para uma discussão sobre esse tema das fronteiras internas por meio de uma análise comparativa entre as discussões da sociologia canônica norte-americana e a visão de escritores afro-americanos sobre a nação americana, consulte o inspirado livro de Roderick A. Ferguson (2004), Aberrations in Black: Toward a Queer of Color Critique.
} 
As fronteiras, no livro de Rossana Rocha Reis, servem como paradigma para a discussão de questões mais espinhosas do que as de políticas de imigração. Por que a homogeneidade de algum tipo (racial, sexual ou religiosa) ainda é critério para o acesso a direitos? As diferenças, alocadas atrás das fronteiras erigidas nesses critérios, são associadas à criminalidade e à barbárie, criam Outros em que as sociedades centrais, ou a minoria privilegiada dos países periféricos, projetam todos os males e temores. O imigrante, estrangeiro, é apenas o Outro mais facilmente reconhecível em sua cor da pele que se soma a traços exóticos, roupas, sotaque ou religião, mas pouco difere de tantos Outros que, internos à nossa própria sociedade, são cotidianamente humilhados e ofendidos, injustamente marcados como abjetos e apartados dos direitos humanos ${ }^{3}$.

Richard Miskolci (richardmiskolci@uol.com.br) é Professor Adjunto de Sociologia do Departamento de Ciências Sociais da Universidade Federal de São Carlos (UFSCar).

\section{REFERÊNCIAS BIBLIOGRÁFICAS}

ANDERSON, P. 2003. Força e consentimento : aspectos da hegemonia americana. Estudos de Sociologia, Araraquara, n. 15, p. 7-30.

BUTLER, J. 2002. Deshacendo el género. Barcelona : Paidós.

CARRILLO, J. 2007. Entrevista com Beatriz Preciado. Cadernos Pagu, Campinas, v. 28, p. 375-405.

FERGUSON, R. A. 2004. Aberrations in Black: Toward a Queer of Color Critique. Minneapolis : Minneapolis University.

REIS, R. R. 2007. Políticas de imigração na França e nos Estados Unidos. São Paulo : Hucitec.

SAID, E. W. 2007. Orientalismo : o Oriente como invenção do Ocidente. São Paulo : Cia. das Letras.

3 Sobre as fronteiras do humano, cf. Butler (2002). 